\title{
Comparative transcriptome and potential antiviral signaling pathways analysis of the gills in the red swamp crayfish, Procambarus clarkii infected with White Spot Syndrome Virus (WSSV)
}

\author{
Zhi-Qiang Du, Yan-Hui Jin \\ School of Life Science and Technology, Inner Mongolia University of Science and Technology, Baotou, Inner \\ Mongolia Autonomous Region, China.
}

\begin{abstract}
Red swamp crayfish is an important model organism for research of the invertebrate innate immunity mechanism. Its excellent disease resistance against bacteria, fungi, and viruses is well-known. However, the antiviral mechanisms of crayfish remain unclear. In this study, we obtained high-quality sequence reads from normal and white spot syndrome virus (WSSV)-challenged crayfish gills. For group normal (GN), 39,390,280 high-quality clean reads were randomly assembled to produce 172,591 contigs; whereas, 34,011,488 high-quality clean reads were randomly assembled to produce 182,176 contigs for group WSSV-challenged (GW). After GO annotations analysis, a total of 35,539 (90.01\%), 14,931 (37.82\%), 28,221 (71.48\%), 25,290 (64.05\%), 15,595 (39.50\%), and 13,848 (35.07\%) unigenes had significant matches with sequences in the Nr, Nt, Swiss-Prot, KEGG, COG and GO databases, respectively. Through the comparative analysis between GN and GW, 12,868 genes were identified as differentially up-regulated DEGs, and 9,194 genes were identified as differentially down-regulated DEGs. Ultimately, these DEGs were mapped into different signaling pathways, including three important signaling pathways related to innate immunity responses. These results could provide new insights into crayfish antiviral immunity mechanism.
\end{abstract}

Keywords: Procambarus clarkii; WSSV; gills; Illumina sequencing; de novo assembly; comparative transcriptomics.

Received: May 12, 2016; Accepted: July 5, 2016.

\section{Introduction}

Unlike vertebrates, invertebrates lack an acquired immune system, but they develop the innate immune system, including cellular and humoral immune responses (Du et al., 2010). When hosts suffer insults or infections from pathogens, these genes can be synergistically mobilized to play their respective roles in cellular defense, especially in the humoral immune response (Taffoni and Pujol, 2015). Further study of the coordination mechanisms of the invertebrate innate immune system by immune-related genes is crucial.

As a typical invertebrate, the red swamp crayfish is used as a model organism to research the response principles of the invertebrate innate immune system. This species is native to Northeastern Mexico and South America and was introduced into China from Japan in the 1930s (Shen et al., 2014). Because of its good fitness characteristics, strong adaptability to a changing environment, and high fecundity, the red swamp crayfish has been widely aquacultured in China (Manfrin et al., 2015). Currently, this

Send correspondence to Zhi-Qiang Du. School of Life Science and Technology, Inner Mongolia University of Science and Technology, No.7 Arding Street, Baotou City, Inner Mongolia Autonomous Region 014010, China. E-mail: nmdzq1981@163.com crayfish has become one of the economically most important aquacultured species. Additionally, the excellent resistances of red swamp crayfish against bacteria, fungi, and viruses are well-known. Recent studies have shown that antibacterial and antifungal mechanisms, such as the Toll and Imd pathways, are strongly conserved (Ermolaeva and Schumacher, 2014). However, the antiviral mechanism in this species remains unclear (Ramos and Fernandez-Sesma, 2015). Systematically identifying the antiviral genes and antivirus-related signaling pathways in this species through transcriptome sequencing is crucial.

Recently, several reports have described transcriptome sequencing results of crayfish tissues, including the hepatopancreas, muscle, ovary, testis, eyestalk, spermary, epidermis, branchia, intestines, and stomach (Shen et al., 2014; Manfrin et al., 2015). However, the transcriptome of crayfish gills or white spot syndrome virus (WSSV)-challenged tissues have not been reported. More importantly, the crayfish gills are in direct contact with the external environment, and gill cells are crucial in the response to external biotic and abiotic factors, especially pathogenic microorganisms (Clavero-Salas et al., 2007). Due to their large number of hemocytes, gills play an important role in cellular host defense against pathogens (Egas et al., 2012). The 
gills are a vital organ that can remove invasive pathogens through an efficient and specific immune response. The study of the gill transcriptome will define an important part of the research field of the innate immune response mechanism.

Next-generation sequencing (NGS) technology has been widely used to explore and uncover vast genetic information in model organisms (Jiang et al., 2014). NGS technology is superior to the traditional Sanger sequencing technology in many aspects. For example, NGS technology can provide enormous amounts of sequence data in much shorter times and at a much lower cost (Martin and Wang, 2011). The expressed sequences produced using NGS technologies are usually 10-to100-fold greater than the number identified by traditional Sanger sequencing technologies (Christie et al., 2015). In this study, the HiSeq sequencing technology was used to sequence the transcriptomes of normal and WSSV-challenged crayfish gills. This approach was used to generate expression profiles and to discover differentially expressed genes (DEGs) between normal and WSSV-challenged crayfish gills. The functions of DEGs were annotated and classified by the Gene Ontology (GO), Cluster of Orthologous Groups (COG), and Kyoto Encyclopedia of Genes and Genomes (KEGG) databases. We believe the data obtained from this study could provide an important resource for research about genes functions, molecular events, and signaling pathways related to the invertebrate antiviral immune response.

\section{Materials and Methods}

\section{Preparation of crayfish tissues and immune challenge}

P. clarkii (weighing approximately 15-20 g) were purchased from an aquaculture commercial market in Hangzhou, Zhejiang Province, China. The collected crayfish were originally cultured in water tanks at $26-28^{\circ} \mathrm{C}$ for 10 days and fed twice a day with artificial food throughout the whole experiment (Li Y et al., 2012). To mimic WSSV infection, WSSV (3.2 $10^{7}$ copies per crayfish) was injected into the abdominal segment of each crayfish (Du et al., 2009). Thirty-six hours after the viral challenge, gills were collected from at least ten WSSV-challenged crayfish (Group WSSV-challenged (GW)). Gills were also collected from ten controls, uninfected crayfish designated as the Group normal (GN). All gills were immediately frozen in liquid nitrogen after collection, and samples were temporarily stored at $-80^{\circ} \mathrm{C}$ until total RNA extraction (Du and Jin, 2015).

\section{RNA isolation and Illumina sequencing}

The two types of gill tissue samples (GN and GW) previously frozen in liquid nitrogen were delivered to the Beijing Genomics Institute-Shenzhen (BGI, Shenzhen, China) for total RNA extraction. In brief, total RNA from crayfish gills was extracted with TRIzol reagent in accordance with manufacturer's protocol (Invitrogen, Life Technologies, Grand Island, NY, USA). The quality of RNA samples treated with DNase I (Invitrogen) was examined for subsequent procedures, including mRNA purification, cDNA library construction and transcriptome sequencing. Approximately $5 \mu \mathrm{g}$ of DNase-treated total RNA was used to construct a cDNA library following the protocols of the Illumina TruSeq RNA Sample Preparation Kit (Illumina, San Diego, CA, USA). After necessary quantification and qualification, the library was sequenced using an Illumina HiSeq 2000 instrument with 100 bp paired-end (PE) reads for both groups.

\section{Transcriptome de novo assembly and analysis}

Transcriptome de novo assembly for all samples was carried out by the RNA-Seq de novo assembly program Trinity (Dedeine et al., 2015). In brief, raw reads generated by the Illumina HiSeq 2000 sequencer were originally trimmed by removing the adapter sequences. After lowquality reads with quality scores $\leq 20$ and short reads with a length $\leq 10 \mathrm{bp}$ were removed, high-quality clean reads were obtained to execute transcriptome de novo assembly using the Trinity software with the default parameters. Generally, three steps were performed, including Inchworm, Chrysalis and Butterfly (He et al., 2015). Initially, high-quality clean reads were processed by Inchworm to form longer fragments, called contigs. Then, contigs were connected by Chrysalis to obtain unigenes, which could not be extended on either end. Unigenes resulted in de Bruijn graphs. Finally, the de Bruijn graphs were processed by Butterfly to obtain transcripts (Li et al., 2013).

\section{Transcriptome annotation and Gene Ontology analysis}

After transcriptome de novo assembly was finished, transcripts were used to carry out annotation tasks, including protein functional annotation, COG functional annotation, GO functional annotation, and pathways annotation. These tasks were based on sequence similarity with known genes. In detail, assembled contigs were annotated with sequences available in the NCBI database, using the BLASTx and BLASTn algorithms (Leng et al., 2015). The unigenes were aligned by a BLASTx search against NCBI protein databases, including the non-redundant $(\mathrm{Nr})$ sequence, Swiss-Prot, KEGG, and COG databases (Li et al., 2015). However, none of the BLASTx hits were aligned by a BLASTn search against the NCBI non-redundant nucleotide database $(\mathrm{Nt})$. The above alignments were executed to establish the homology of sequences with known genes (with a cutoff E-value $\leq 10^{-5}$ ) (Li ST et al., 2012). Then, the best alignment results were used to decide the sequence orientation and the protein coding region prediction (CDS) of the unigenes. Functional annotation was executed with Gene Ontology (GO) terms (www.geneontology.org) that 
were analyzed using the Blast2GO software (http://www.blast2go.com/b2ghome) (Conesa et al., 2005). Based on the KEGG database, the complex biological behavior of the genes was analyzed through pathway annotation.

\section{Identification of differentially expressed genes}

To acquire the expression profiles of transcripts in crayfish gills, cleaned reads were first mapped to all transcripts using Bowtie software (Langmead and Salzberg, 2012). Then, DEGs were obtained on the basis of fragments per kilobase of exon per million fragments mapped (FPKM) of the genes, followed by a False Discovery Rate (FDR) control, to correct for the P-value (Mortazavi et al., 2008). DEGs were identified using EDGER software (empirical analysis of digital gene expression data in R) (Robinson et al., 2010). In the analysis process, the filtering threshold was set as a 0.5 FDR control. Ultimately, an FDR $\leq 0.001$ and the absolute value of the $\log 2$ Ratio $\geq 1$ were used as the filtering threshold to determine the significance of DEGs (Banani et al., 2016). DEGs (GW vs GN) were identified through a comparative analysis of the above data.

\section{Quantitative real-time PCR}

Quantitative real-time PCR (qRT-PCR) methods were used to determine the RNA levels for 15 selected genes related to innate immune response (Wang et al., 2015). For the qRT-PCR analysis, cDNA templates from the samples were diluted 20 -fold in nuclease-free water and used as templates for the PCR reaction. Gene-specific primers sequences were designed using Primer Premier 6 software on the basis of each identified gene sequence from the transcriptome library (Lu et al., 2014). The specific primers $P c-18 S R N A$-qRT-F (5'-tct tct tag agg gat tag cgg-3') and $P c-18 S R N A$-qRT-R (5' -aag ggg att gaa cgg gtt a-3') were used to amplify the $18 S R N A$ gene as an internal control. qRT-PCR was performed following the manufacturer's instructions of SYBR Premix Ex Taq (Takara, Dalian, China) using a real-time thermal cycler (Bio-Rad, USA) in a total volume of $10 \mu \mathrm{l}$ containing $5 \mu \mathrm{l}$ of 2 Premix Ex Taq, $1 \mu \mathrm{l}$ of the 1:20 diluted cDNA, and $2 \mu \mathrm{l}(1 \mu \mathrm{M})$ each of the forward and reverse primers. The amplification procedure was comprised of an initial denaturation step at $95^{\circ} \mathrm{C}$ for $3 \mathrm{~min}$, followed by 40 cycles of $95^{\circ} \mathrm{C}$ for $15 \mathrm{~s}, 58^{\circ} \mathrm{C}$ for $40 \mathrm{~s}$, and melting from $65^{\circ} \mathrm{C}$ to $95^{\circ} \mathrm{C}$. Three parallel experiments were performed (Du et al., 2015). Furthermore, the differentially expressed levels of the target genes between the groups were calculated by the $2^{-\Delta \Delta C \mathrm{CT}}$ analysis method (Livak and Schmittgen, 2001). Data obtained were subjected to a statistical analysis, followed by an unpaired sample $t$-test. A significant difference was assigned when $\mathrm{P}$ $<0.05$ or $\mathrm{P}<0.01$.

\section{Results}

\section{Illumina sequencing of the crayfish gills transcriptome}

After the GN sample was cleaned and quality-tested, $39,390,280$ clean reads were identified from 40,384,330 raw reads, which corresponded to $3,939,028,000$ total nucleotides (nt). The Q20 percentage (percentage of bases whose quality was $\geq 20$ in the clean reads), $N$ percentage (percentage of uncertain bases after filtering) and GC percentage were $98.02 \%, 0.00 \%$ and $41.52 \%$, respectively (Table 1). For the GW sample, $34,011,488$ clean reads were identified from $34,840,334$ raw reads, which corresponded to $3,401,148,800$ total nucleotides (nt). The Q20 percentage, $\mathrm{N}$ percentage and GC percentage were $98.04 \%, 0.00 \%$ and $41.98 \%$, respectively (Table 1 ). All these sequences were used for further analysis.

\section{De novo assembly of the transcriptome}

After the low-quality and short length reads were removed, high-quality clean reads were obtained, and transcriptome de novo assembly was performed using Trinity software with its default parameters (Ali et al., 2015). For GN, 39,390,280 high-quality clean reads were randomly assembled to produce 172,591 contigs with an N50 of 690 bp. The contigs were further assembled and clustered into 94,479 unigenes with a mean length of $644 \mathrm{nt}$, which were composed of 10,931 distinct clusters and 83,548 distinct singletons. The N50 of the above unigenes was $1,345 \mathrm{bp}$ (Table 2). For GW, 34,011,488 high-quality clean reads were randomly assembled to produce 182,176 contigs with an N50 of $528 \mathrm{bp}$. The contigs were further assembled and clustered into 95,959 unigenes with a mean length of 558 nt, which were composed of 8,299 distinct clusters and 87,660 distinct singletons. The N50 of the above unigenes was $1,007 \mathrm{bp}$ (Table 2).

For GN, the lengths of unigenes were primarily distributed between $200 \mathrm{nt}$ and 2,000 nt. The percentage of unigenes with lengths from $201-500$ bp was $70.30 \%$ $(66,423)$, from $501-1,000$ bp was $14.07 \%(13,294)$, from $1,001-1,500 \mathrm{bp}$ was $5.40 \%(5,099)$, from $1,501-2,000 \mathrm{bp}$ was $3.23 \%(3,048)$, and $>2,000$ bp was $7.00 \%(6,615)$. For $\mathrm{GW}$, the percentage of unigenes with lengths from 201-500

Table 1 - Summary of Illumina sequencing output for the GN and the GW.

\begin{tabular}{lcccccc}
\hline Sample & Total raw reads & Total clean reads & Total clean nucleotides (nt) & Q20 percentage & N percentage & GC percentage \\
\hline GN-gills & $40,384,330$ & $39,390,280$ & $3,939,028,000$ & $98.02 \%$ & $0.00 \%$ & $41.52 \%$ \\
GW-gills & $34,840,334$ & $34,011,488$ & $3,401,148,800$ & $98.04 \%$ & $0.00 \%$ & $41.98 \%$ \\
\hline
\end{tabular}


Table 2 - Summary of the assembly analysis for GN and GW.

\begin{tabular}{lcccc}
\hline Dataset name & \multicolumn{2}{c}{ Group normal (GN) } & \multicolumn{2}{c}{ Group WSSW-challenged (GW) } \\
\cline { 2 - 5 } & Contigs & Unigenes & Contigs & Unigenes \\
\hline Total number & 172,591 & 94,479 & 182,176 & 95,959 \\
Total length (nt) & $60,746,050$ & $60,823,435$ & $57,529,732$ & $53,499,561$ \\
Mean length (nt) & 352 & 644 & 316 & 558 \\
N50 & 690 & 1,345 & 528 & 1,007 \\
Total consensus sequences & - & 94,479 & - & 95,959 \\
Distinct clusters & - & 10,931 & - & 8,229 \\
Distinct singletons & - & 83,548 & - & 87,660 \\
\hline
\end{tabular}

bp was $74.12 \%(71,124)$, from $501-1,000$ bp was $13.44 \%$ $(12,897)$, from $1,001-1,500 \mathrm{bp}$ was $4.91 \%(4,711)$, from $1,501-2,000$ bp was $2.58 \%(2,479)$, and $>2,000$ bp was $4.95 \%(4,748)$.

\section{Functional annotation of predicted proteins}

Transcripts were combined with data from two other transcriptomes from Mousavi et al. (2014). First, sequence annotation was carried out on the basis of unigenes from the merged group (Garcia-Seco et al., 2015). Then, the putative functions of all unigenes were analyzed based on GO and COG classifications (Young et al., 2010). In the present study, based on the merged group transcriptome data (98,676 unigenes), a basic sequence analysis was performed to understand the functions of the crayfish gill transcriptome before the analysis of DEGs related to WSSV infection. Among the predicted sequences, a total of 39,482 unigene sequences were annotated using a BLASTx alignment with an E-value $\leq 10^{-5}$. A total of 35,539 (90.01\%), $14,931(37.82 \%), 28,221 \quad(71.48 \%), 25,290(64.05 \%)$, $15,595(39.50 \%)$, and $13,848(35.07 \%)$ unigenes had significant matches with sequences in the $\mathrm{Nr}$, Nt, Swiss-Prot, KEGG, COG and GO databases, respectively. In brief, a total of 35,539 transcripts $(90.01 \%$ of all annotated transcripts) had significant hits in the $\mathrm{Nr}$ protein database. The gene names of the top BLAST hits were assigned to each transcript with significant hits. Among them, 2,682 (7.55\%) transcripts were matched with genes from Paramecium tetraurelia, 2,362 (6.65\%) transcripts were matched with genes from Daphnia pulex; 3,265 (9.19\%) transcripts were matched with genes from Tetrahymena thermophila; 1,302 (3.66\%) transcripts were matched with genes from Tribolium castaneum; 1,292 (3.64\%) transcripts were matched with genes from Ichthyophthirius multifiliis; and 929 transcripts were matched with genes from Pediculus humanus.

The GO classification is an international standardized gene function classification system that provides a dynamically updated controlled vocabulary and an exactly defined conception to describe genes' characteristics and their products in any organism (Di et al., 2015). The GO classification includes three ontologies: biological process, cellu- lar component and molecular function (Chen et al., 2015). In this study, a GO analysis was carried out using Blast $2 \mathrm{GO}$ software. A total of 13,848 transcripts annotated in the GO database were categorized into 58 functional groups, including the three main GO ontologies (Figure 1). Among these functional groups, "biological regulation", "cellular process", "metabolic process", "cell”, "single-organism process", "cell part", "binding", and "catalytic activity" terms were predominant.

COGs were delineated by comparing protein sequences encoded in complete genomes, representing major phylogenetic lineages (Tatusov et al., 2003). COG classification analysis is also an important method for unigene functional annotation and evolutionary research (Lai and Lin, 2013). We used the COG classification to further evaluate the completeness of the transcriptome library and the effectiveness of the annotation methods. A total of 15,959 unigenes were mapped to 25 different COG categories. In these 25 different categories, the largest COG group was category R, representing "general function prediction only" $(6,435$ unigenes, $41.26 \%)$, followed by category J, representing "translation, ribosomal structure and biogenesis" $(3,347$ unigenes, $21.46 \%)$; category $\mathrm{K}$, representing "transcription" (3,044 unigenes, 19.52\%); and category L, representing "replication, recombination and repair" $(2,802$ unigenes, 17.97\%; Figure 2).

KEGG is a bioinformatics resource for linking genomes to life and the environment (Mao et al., 2005). The KEGG pathway database records networks of molecular interactions in cells and variants specific to particular organisms (Chen et al., 2015). The genes from the merged groups (GN and GW) were categorized using the KEGG database to obtain more information to predict the unigene functions (Feng et al., 2015). A total of 25,290 unigenes were classified into $257 \mathrm{KEGG}$ pathways. Among these KEGG pathways, the top 30 statistically significant KEGG classifications are shown in Table 3. Moreover, some important innate immunity-related pathways were predicted in this KEGG database, including Vibrio cholerae infection (1092 sequences, $4.32 \%$ ), focal adhesion (910 sequences, 3.6\%), Epstein-Barr virus infection (860 sequences, 3.40\%), lysosome (610 sequences, 2.41\%), HTLV-I infection (596 
sequences, $2.36 \%$ ), Herpes simplex infection (593 sequences, 2.34\%), salmonella infection (576 sequences, $2.28 \%$ ), MAPK signaling pathway (542 sequences, 2.14\%), adherens junction (467 sequences, 1.85\%), and so on (Table 3). Notably, the insulin signaling pathway, Wnt signaling pathway, mRNA surveillance pathway, endocytosis,

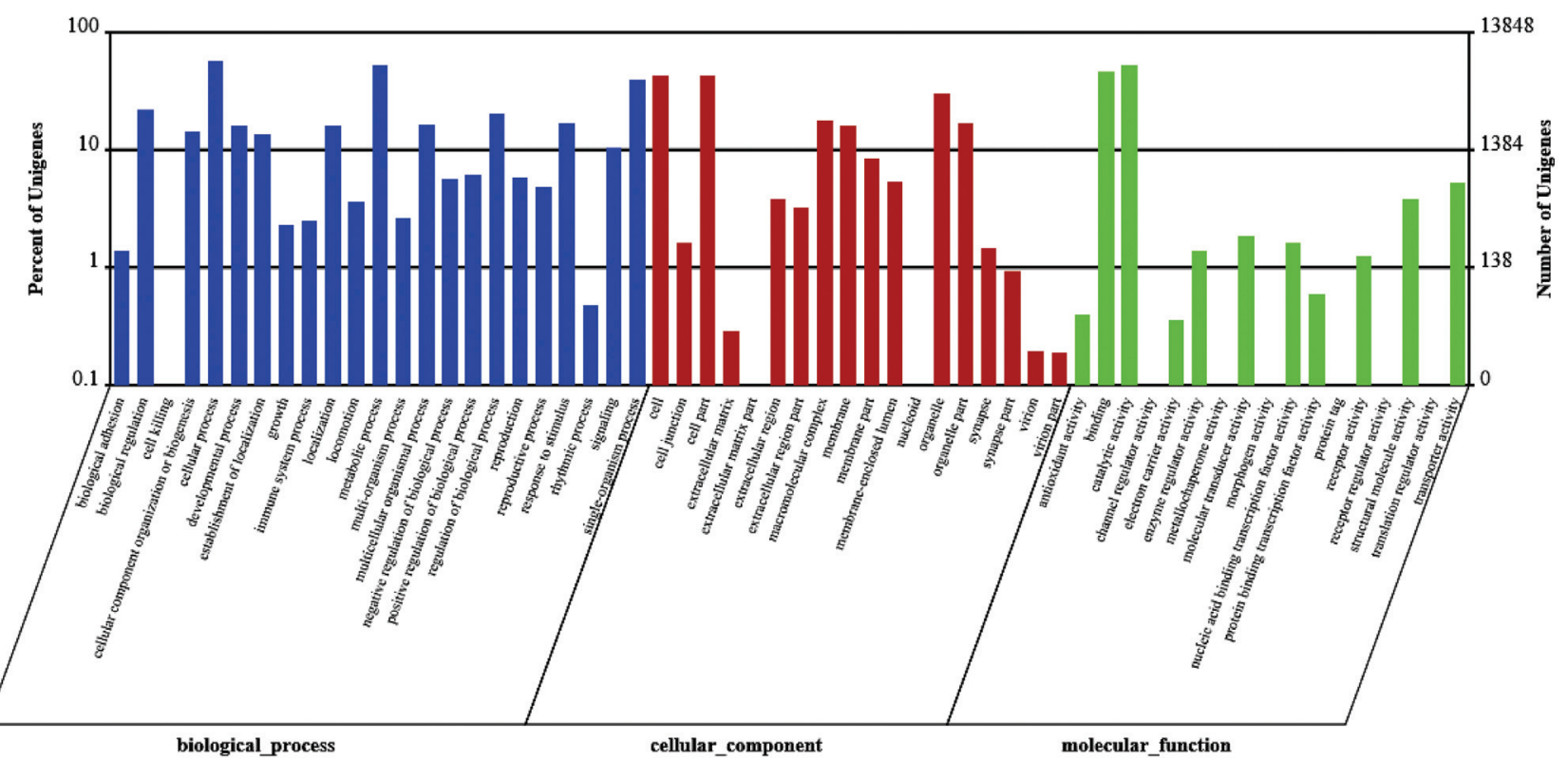

Figure 1 - Gene ontology (GO) classification of transcripts from the two gill samples (GN and GW). The three main GO categories include biological process (blue), cellular component (red), and molecular function (green).

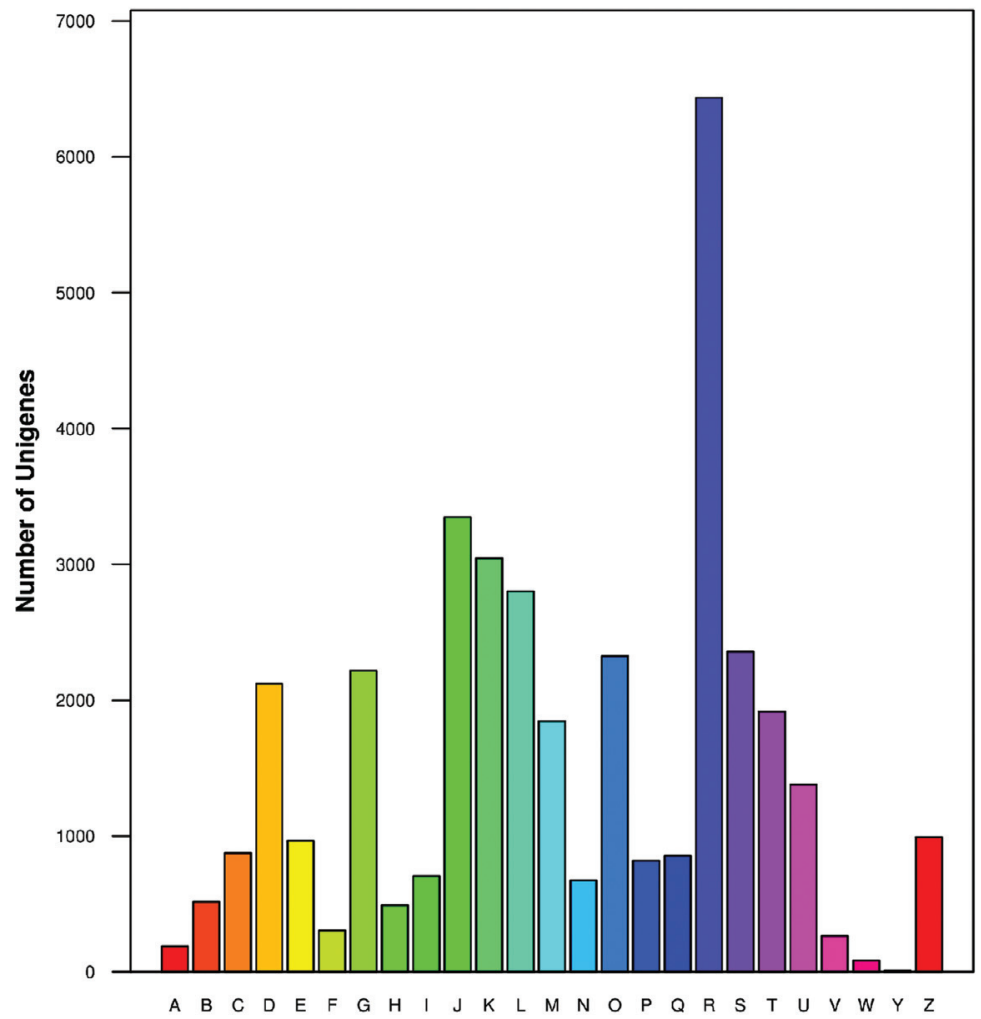

Function Class

\author{
A: RNA processing and modification \\ B: Chromatin structure and dynamics \\ C: Energy production and conversion \\ D: Cell cycle control, cell division, chromosome partitioning \\ E: Amino acid transport and metabolism \\ F: Nucleotide transport and metabolism \\ G: Carbohydrate transport and metabolism \\ $\mathrm{H}$ : Coenzyme transport and metabolism \\ I: Lipid transport and metabolism \\ $\mathrm{J}$ : Translation, ribosomal structure and biogenesis \\ K: Transcription \\ L: Replication, recombination and repair \\ M: Cell wall/membrane/envelope biogenesis \\ $\mathrm{N}$ : Cell motility \\ O: Posttranslational modification, protein turnover, chaperones \\ $P$ : Inorganic ion transport and metabolism \\ $\mathrm{Q}$ : Secondary metabolites biosynthesis, transport and catabolism \\ $\mathrm{R}$ : General function prediction only \\ S: Function unknown \\ T: Signal transduction mechanisms \\ U: Intracellular trafficking, secretion, and vesicular transport \\ $\mathrm{V}$ : Defense mechanisms \\ $W$ : Extracellular structures \\ Y: Nuclear structure \\ Z: Cytoskeleton
}

Figure 2 - Cluster of orthologous groups (COG) classification of putative proteins. 
Table 3 - Top 30 statistically significant KEGG classifications.

\begin{tabular}{|c|c|c|c|}
\hline No. & Pathway & Pathway definition & $\begin{array}{l}\text { Number of } \\
\text { sequences }\end{array}$ \\
\hline 1 & path: ko01100 & Metabolic pathways & $3371(13.33 \%)$ \\
\hline 2 & path: ko05146 & Amoebiasis & $1148(4.54 \%)$ \\
\hline 3 & path: ko05110 & $\begin{array}{l}\text { Vibrio cholerae in- } \\
\text { fection }\end{array}$ & $1092(4.32 \%)$ \\
\hline 4 & path: ko05016 & $\begin{array}{l}\text { Huntington's dis- } \\
\text { ease }\end{array}$ & $973(3.85 \%)$ \\
\hline 5 & path: ko04810 & $\begin{array}{l}\text { Regulation of actin } \\
\text { cytoskeleton }\end{array}$ & $950(3.76 \%)$ \\
\hline 6 & path: ko04510 & Focal adhesion & $910(3.6 \%)$ \\
\hline 7 & path: ko03040 & Spliceosome & $894(3.53 \%)$ \\
\hline 8 & path: ko05200 & Pathways in cancer & $879(3.48 \%)$ \\
\hline 9 & path: ko05169 & $\begin{array}{l}\text { Epstein-Barr virus } \\
\text { infection }\end{array}$ & $860(3.4 \%)$ \\
\hline 10 & path: ko03013 & RNA transport & $847(3.35 \%)$ \\
\hline 11 & path: ko00230 & Purine metabolism & $781(3.09 \%)$ \\
\hline 12 & path: ko04145 & Phagosome & $643(2.54 \%)$ \\
\hline 13 & path: ko04144 & Endocytosis & $638(2.52 \%)$ \\
\hline 14 & path: ko04270 & $\begin{array}{l}\text { Vascular smooth } \\
\text { muscle contraction }\end{array}$ & $633(2.5 \%)$ \\
\hline 15 & path: ko03010 & Ribosome & $632(2.5 \%)$ \\
\hline 16 & path: ko04530 & Tight junction & $616(2.44 \%)$ \\
\hline 17 & path: ko00240 & $\begin{array}{l}\text { Pyrimidine metabo- } \\
\text { lism }\end{array}$ & $616(2.44 \%)$ \\
\hline 18 & path: ko04142 & Lysosome & $610(2.41 \%)$ \\
\hline 19 & path: ko04141 & $\begin{array}{l}\text { Protein processing } \\
\text { in endoplasmic re- } \\
\text { ticulum }\end{array}$ & $607(2.4 \%)$ \\
\hline 20 & path: ko05166 & HTLV-I infection & $596(2.36 \%)$ \\
\hline 21 & path: ko05168 & $\begin{array}{l}\text { Herpes simplex in- } \\
\text { fection }\end{array}$ & $593(2.34 \%)$ \\
\hline 22 & path: ko05132 & Salmonella infection & $576(2.28 \%)$ \\
\hline 23 & path: ko03015 & $\begin{array}{l}\text { mRNA surveillance } \\
\text { pathway }\end{array}$ & $563(2.23 \%)$ \\
\hline 24 & path: ko04120 & $\begin{array}{l}\text { Ubiquitin-mediated } \\
\text { proteolysis }\end{array}$ & $557(2.2 \%)$ \\
\hline 25 & path: ko04010 & $\begin{array}{l}\text { MAPK signaling } \\
\text { pathway }\end{array}$ & $542(2.14 \%)$ \\
\hline 26 & path: ko04020 & $\begin{array}{l}\text { Calcium signaling } \\
\text { pathway }\end{array}$ & $538(2.13 \%)$ \\
\hline 27 & path: ko05414 & $\begin{array}{l}\text { Dilated } \\
\text { cardiomyopathy }\end{array}$ & $524(2.07 \%)$ \\
\hline 28 & path: ko05164 & Influenza A & $517(2.04 \%)$ \\
\hline 29 & path: ko05410 & $\begin{array}{l}\text { Hypertrophic } \\
\text { cardiomyopathy } \\
\text { (HCM) }\end{array}$ & $495(1.96 \%)$ \\
\hline 30 & path: ko04970 & Salivary secretion & $493(1.95 \%)$ \\
\hline
\end{tabular}

phagosome, and tight junction functions were present in the top 40 statistically significant KEGG classifications.

\section{Differentially expressed genes analysis of crayfish gills after WSSV infection}

Previous sequence analysis and annotation for all unigenes in the merged group provided some useful information to analyze the crayfish gills transcriptome. Even more importantly, variation in the gene expression level of crayfish gills after WSSV infection was expected. In this study, an FDR $\leq 0.001$ and an absolute value of $\log 2$ Ratio $\geq$ 1 were used as the filtering threshold to determine upregulated or down-regulated genes between normal and WSSV-challenged crayfish gills. As shown in Figure 3, a total of 22,062 DEGs with a > two-fold change were identified by the comparative analysis between the GN and GW samples, including 12,868 differentially up-regulated and 9,194 differentially down-regulated genes. In brief, among these 22,062 DEGs, 12,826 genes were expressed in both GN and GW, including 3,632 differentially up-regulated genes and 9,194 differently down-regulated genes. Moreover, 9,236 genes were only expressed in the GW sample.

To confirm the biological function of DEGs between GN and GW, GO classification and KEGG pathway analysis for the DEGs were carried out (Gupta et al., 2015). A GO classification analysis was conducted on the annotated transcripts using Blast2GO. As shown in Figure 4, a total of 4,702 DEGs were identified after a comparison between GN and GW. Significantly altered expression (up/down) was present for $45 \mathrm{GO}$ terms $(\mathrm{P}<0.05)$ and $32 \mathrm{GO}$ terms, respectively $(\mathrm{P}<0.01)$. Among the former group, there were 15,8 , and $22 \mathrm{GO}$ terms that belonged to "cellular component (C)", "molecular function (F)" and "biological process $(\mathrm{P})$ ", respectively. Among the latter group, there were 14,3 , and $15 \mathrm{GO}$ terms that belonged to "cellular component (C)", "molecular function (F)" and "biological

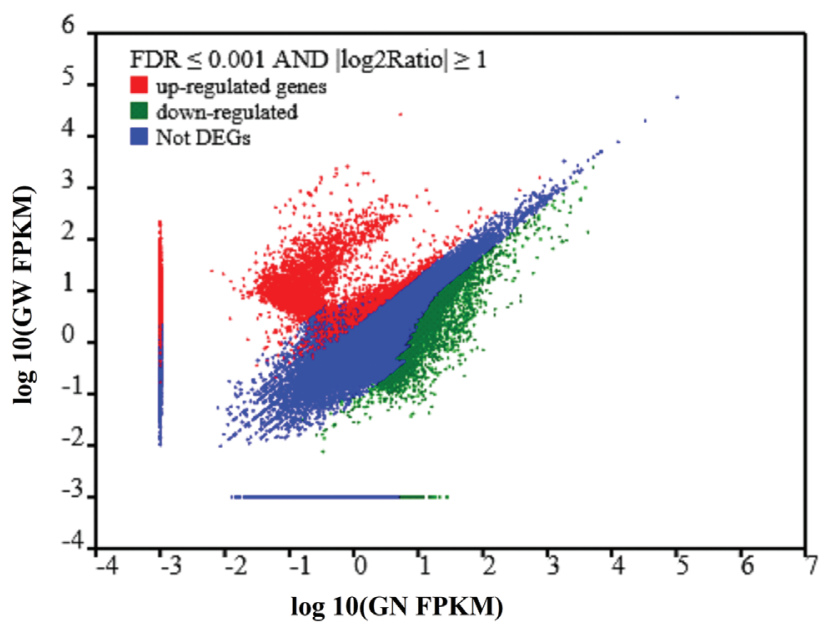

Figure 3 - Comparative analysis of the gene expression levels for two transcript libraries between normal (GN) and WSSV-challenged (GW) crayfish gills. Red dots represent transcripts significantly up-regulated in $\mathrm{GW}$, while green dots represent significantly down-regulated transcripts. The parameters "FDR $\leq 0.001$ " and " $\log 2$ Ratio $\mid \geq 1$ " were used as the threshold to judge the significance of gene expression differences. 


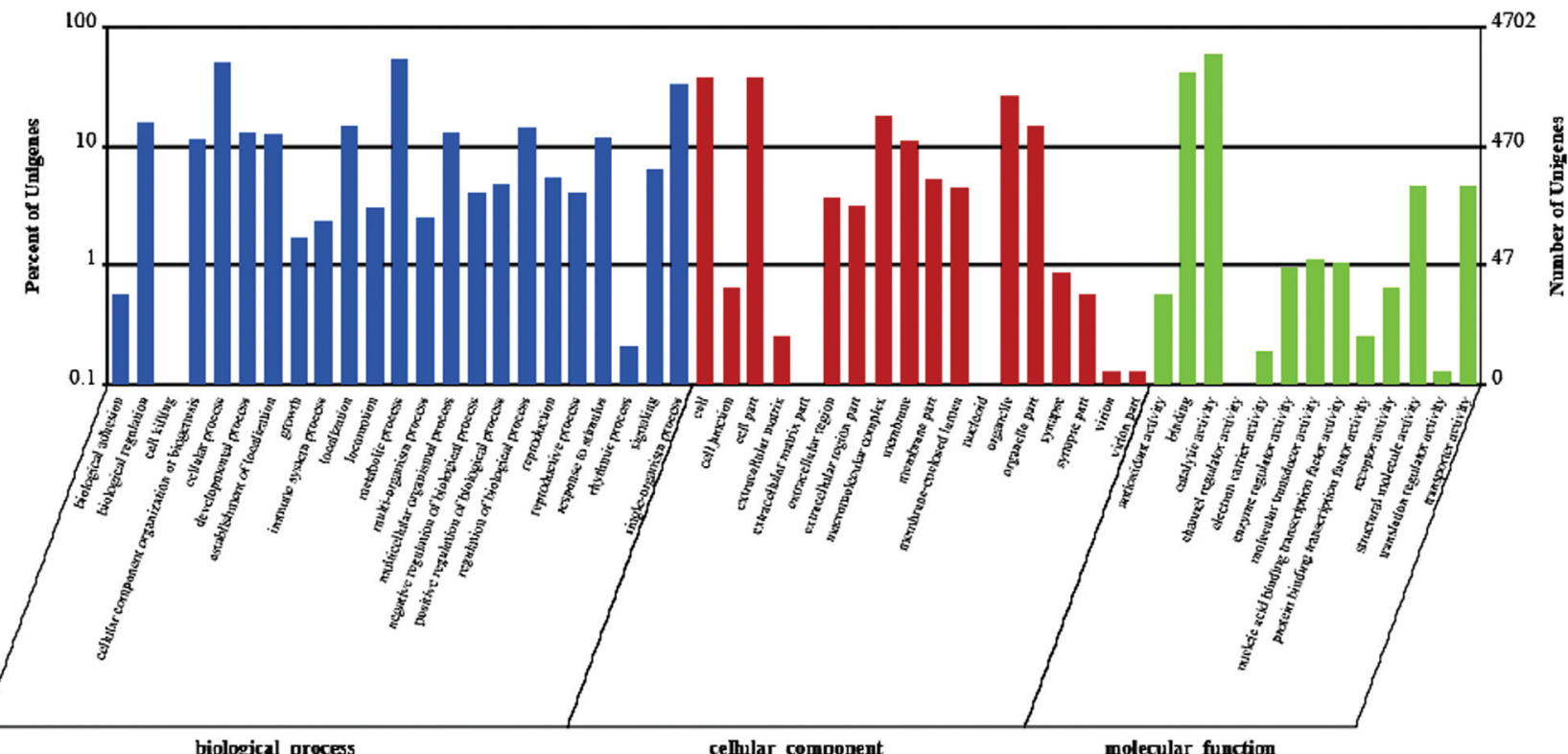

Figure 4 - Gene ontology (GO) classification analysis of differentially expressed genes (DEGs) between GN and GW. The three main GO categories include biological process (blue), cellular component (red), and molecular function (green).

process (P)", respectively. The GO analysis revealed that gene clusters with significant differential expression mainly concentrated in the aspect of biological process.

Next, all DEGs were mapped in the KEGG database to search for genes involved in innate immune response or signaling pathways. A total of 7,918 DEGs were assigned to $256 \mathrm{KEGG}$ pathways. The KEGG pathway analysis identified 100 pathways that were significantly changed $(\mathrm{P}$ $<0.05$ ), of which 80 reached a higher level of significance

Table 4 - Top 80 differentially expressed pathways between GW and GN.

\begin{tabular}{|c|c|c|c|c|}
\hline No. & Pathway & $\begin{array}{l}\text { Number of } \\
\text { DEGs }\end{array}$ & P-value & Pathway ID \\
\hline 1 & $\begin{array}{l}\text { Glycolysis / } \\
\text { Gluconeogenesis }\end{array}$ & $99(1.25 \%)$ & $3,78 \mathrm{E}-199$ & ko00010 \\
\hline 2 & RNA transport & $219(2.77 \%)$ & $4.26 \mathrm{E}-92$ & ko03013 \\
\hline 3 & $\begin{array}{l}\text { Epithelial cell signal- } \\
\text { ing }\end{array}$ & $64(0.81 \%)$ & $3.64 \mathrm{E}-19$ & ko05120 \\
\hline 4 & Apoptosis & $73(0.92 \%)$ & $2.29 \mathrm{E}-17$ & ko04210 \\
\hline 5 & Allograft rejection & $3(0.04 \%)$ & $7.15 \mathrm{E}-15$ & ko05330 \\
\hline 6 & $\begin{array}{l}\text { Renin-angiotensin sys- } \\
\text { tem }\end{array}$ & $31(0.39 \%)$ & $2.42 \mathrm{E}-14$ & ko04614 \\
\hline 7 & p53 signaling pathway & $55(0.69 \%)$ & $1.62 \mathrm{E}-12$ & ko04115 \\
\hline 8 & $\begin{array}{l}\text { mTOR signaling path- } \\
\text { way }\end{array}$ & $126(1.59 \%)$ & $2.34 \mathrm{E}-12$ & ko04150 \\
\hline 9 & Endocytosis & $177(2.24 \%)$ & $2.35 \mathrm{E}-11$ & ko04144 \\
\hline 10 & $\begin{array}{l}\text { Staphylococcus aureus } \\
\text { infection }\end{array}$ & $36(0.45 \%)$ & $1.87 \mathrm{E}-10$ & ko05150 \\
\hline 11 & Leishmaniasis & $28(0.35 \%)$ & $4.16 \mathrm{E}-10$ & ko05140 \\
\hline 12 & $\begin{array}{l}\text { Protein processing in } \\
\text { ER }\end{array}$ & $249(3.14 \%)$ & $9.51 \mathrm{E}-10$ & ko04141 \\
\hline
\end{tabular}

$(\mathrm{P}<0.01)$ in the GW compared with the GN. Some of the significantly altered KEGG pathways were related to the innate immunity response, including apoptosis, Staphylococcus aureus infection, lysosome, melanogenesis, TGFbeta signaling pathway, NOD-like receptor signaling pathway, PPAR signaling pathway, focal adhesion, toll-like receptor signaling pathway, and bacterial invasion of epithelial cells (Table 4).

\begin{tabular}{lllll}
\hline No. & Pathway & $\begin{array}{l}\text { Number of } \\
\text { DEGs }\end{array}$ & P-value & Pathway ID \\
\hline 13 & $\begin{array}{l}\text { Synthesis and degrada- } \\
\text { tion of ketone bodies }\end{array}$ & $12(0.15 \%)$ & $1.05 \mathrm{E}-09$ & ko00072 \\
14 & $\begin{array}{l}\text { Metabolism of xeno- } \\
\text { biotics by P450 }\end{array}$ & $50(0.63 \%)$ & $3.28 \mathrm{E}-09$ & ko00980 \\
15 & $\begin{array}{l}\text { Phe, Tyr and Try } \\
\text { biosynthesis }\end{array}$ & $13(0.16 \%)$ & $4.22 \mathrm{E}-09$ & ko00400 \\
16 & $\begin{array}{l}\text { Taurine and hypo- } \\
\text { taurine metabolism }\end{array}$ & $5(0.06 \%)$ & $5.99 \mathrm{E}-09$ & ko00430 \\
17 & $\begin{array}{l}\text { Collecting duct acid } \\
\text { secretion }\end{array}$ & $44(0.56 \%)$ & $9.75 \mathrm{E}-09$ & ko04966 \\
18 & $\begin{array}{l}\text { Chronic myeloid leu- } \\
\text { kemia }\end{array}$ & $43(0.54 \%)$ & $2.35 \mathrm{E}-08$ & ko05220 \\
19 & $\begin{array}{l}\text { Pentose phosphate } \\
\text { pathway }\end{array}$ & $30(0.38 \%)$ & $2.69 \mathrm{E}-08$ & ko00030 \\
20 & $\begin{array}{l}\text { ABC transporters } \\
\text { Thyroid cancer }\end{array}$ & $112(1.41 \%)$ & $7.07 \mathrm{E}-08$ & ko02010 \\
22 & $\begin{array}{l}\text { Lysosome } \\
23\end{array}$ & $\begin{array}{l}\text { Morphine addiction } \\
40.23 \%)\end{array}$ & $1.21 \mathrm{E}-07$ & ko05216 \\
$49.38 \%)$ & $2.02 \mathrm{E}-07$ & ko04142 \\
$2.35 \mathrm{E}-07$ & ko05032
\end{tabular}


Table 4 (cont.)

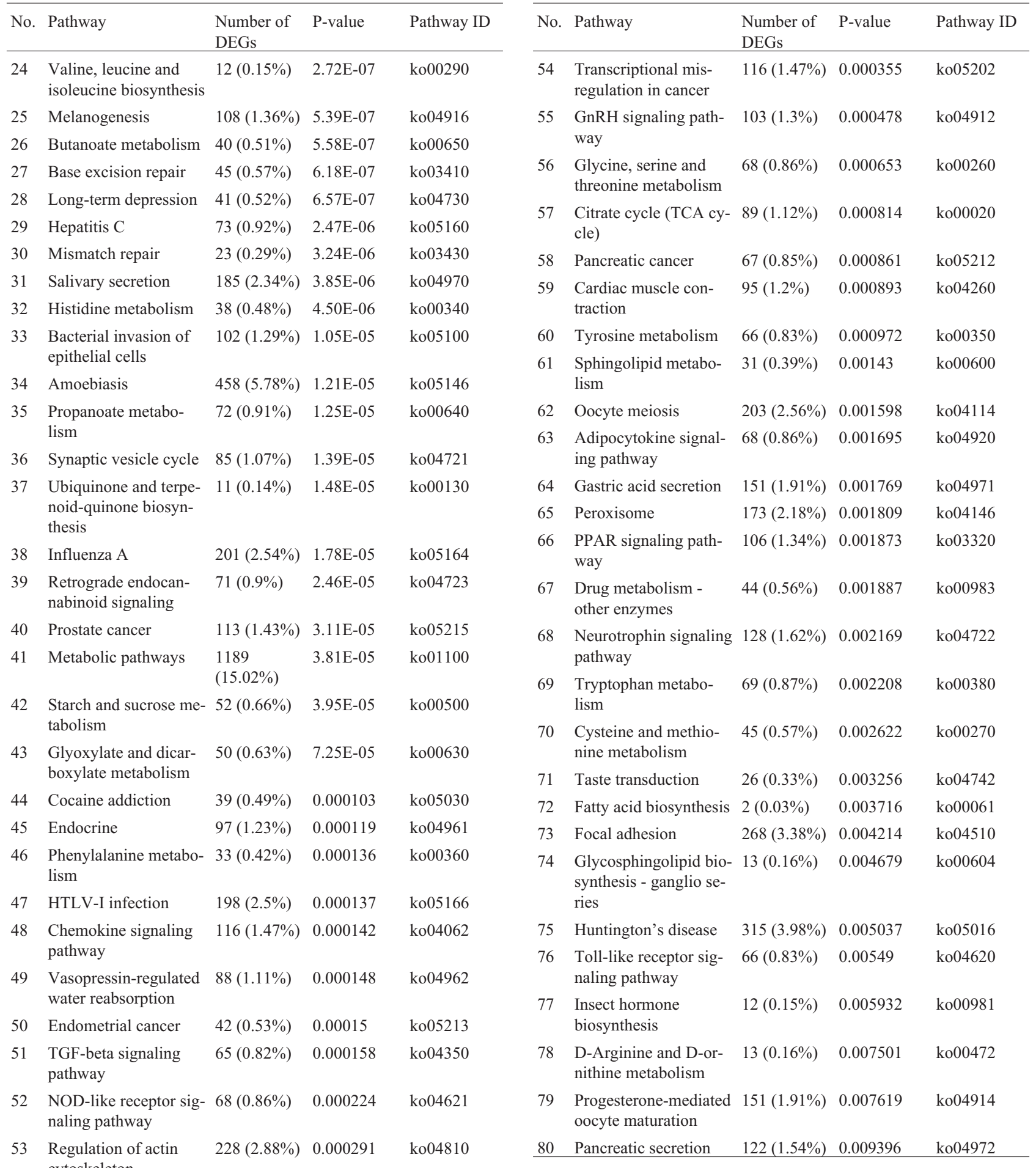

\section{Analysis of transcriptome data by qRT-PCR}

We chose 15 genes related to the innate immunity response and evaluated their differential expression level between the GW and the GN, using qRT-PCR (Gao et al., 2015). For these candidate genes, the variation trends of the

qRT-PCR expression profiles were found to be consistent with the RNA-seq data (Table 5). There were similar trends in the genes that were up-/down-regulated between the qRT-PCR and the transcriptome data, implying that the differential expression changes identified by the RNA-Seq data were reliable. 
Table 5 - Comparison of relative fold change of RNA-Seq and qRT-PCR results between GW and GN.

\begin{tabular}{|c|c|c|c|}
\hline \multirow[t]{2}{*}{ Gene name } & \multirow[t]{2}{*}{ Protein identity } & \multicolumn{2}{|c|}{ Fold variation $(\mathrm{GW} / \mathrm{GN})$} \\
\hline & & transcriptome & qRT-PCR \\
\hline CL3739.Contig3_All & Lysozyme & 53.80 (up) & 20.51 (up) \\
\hline Unigene68353_All & Integral membrane protein & 42.34 (up) & 25.63 (up) \\
\hline Unigene56169_All & Apoptosis-regulated protein & 26.33 (up) & 16.77 (up) \\
\hline CL88.Contig2_All & Serine protease inhibitor & 24.41 (up) & 18.52 (up) \\
\hline CL4190.Contig1_All & Chitin binding-like protein & 7.29 (up) & 16.87 (up) \\
\hline CL1412.Contig2_All & Interleukin enhancer binding factor & 4.83 (up) & 2.46 (up) \\
\hline CL6575.Contig2_All & Anti-lipopolysaccharide factor & 4.11 (up) & 5.63 (up) \\
\hline CL818.Contig4_All & Dicer 2 & 4.09 (up) & 3.48 (up) \\
\hline CL1181.Contig4_All & Integrin & 3.59 (up) & 8.33 (up) \\
\hline CL6415.Contig2_All & Cathepsin C & 3.49 (up) & 7.38 (up) \\
\hline CL2737.Contig2_All & Ras & 3.16 (up) & 8.22 (up) \\
\hline CL2514.Contig2_All & NF-kappa B inhibitor alpha & 0.46 (down) & 0.19 (down) \\
\hline Unigene789_All & Clip domain serine proteinase 3 & 0.47 (down) & $0.66($ down $)$ \\
\hline Unigene31753_All & Tyrosine-protein kinase isoform & 0.36 (down) & 0.17 (down) \\
\hline CL3161.Contig1_All & Phosphoinositide 3-kinase isoform & 0.49 (down) & 0.88 (down) \\
\hline
\end{tabular}

\section{Discussion}

Transcriptome sequencing is an effective method for obtaining genomic information from non-model organism with no available reference genome. The genomic information is the important basis to discover molecular mechanisms of the organism's biological traits. Due to its superior antiviral immune characteristics, crayfish has become the economically most important aquacultured species in China. However, research on the antiviral molecular mechanisms is scarce. In the present study, de novo assembled transcriptomes of crayfish gills were analyzed, and a large number of sequences were obtained. DEGs that differed in expression between normal and WSSV-challenged crayfish gills were studied in detail. All these transcriptomes data are valuable to shed light on the antiviral immune mechanism of crayfish.

So far, several studies based on the NGS technology have reported transcriptome sequencing results for crayfish tissues, including hepatopancreas, muscle, ovary, testis, eyestalk, spermary, epidermis, branchia, intestines, and stomach. Those studies mainly focused on gonadal development (Jiang et al., 2014), neuroendocrinology (Manfrin et al., 2015), and genetic markers (Shen et al., 2014). Transcriptome sequencing results for crayfish antiviral immunity are very limited, and very few works about crayfish transcriptomes changing after virus challenge are reported. So, the aim of the present study was an in-depth analysis of DEGs by functional annotation, orthologous protein clustering, and annotation of signaling pathways related to the immune system to determine the underlying mechanisms involved in the crayfish anti-WSSV immune response.
Based on the KEGG pathway analysis for DEGs between the GN and GW, some signaling pathways related to the invertebrate innate immune system were identified. Apoptosis is an indispensable physiologic and biochemical process that evolved in eukaryotes to remove excessive and damaged cells to maintain organismal integrity. Apoptosis plays an important role in the processes of cell differentiation, development, and proliferation (Elmore, 2007). When organisms encounter a pathogen infection and other environment stresses, apoptosis can be mobilized to regulate cell metabolism (Igney and Krammer, 2002). Cell proliferation controlled by apoptosis has been reported to be involved in the antiviral immunity response (Du et al., 2013). In the present study, 73 representative innate immunerelated genes were significantly differentially expressed in the apoptosis signaling pathway. Within this group, 52 DEGs were significantly up-regulated, and 21 DEGs were significantly down-regulated (Figure 5).

Melanogenesis is an important biochemical pathway responsible for melanin synthesis that is controlled by complex regulatory mechanisms (Kim, 2015). Melanin is a vital intermediate in the arthropod humoral immunity response. In the present study, 108 innate immunity-related genes in the melanogenesis pathway were significantly differentially expressed, including 73 significantly up-regulated genes and 35 significantly down-regulated genes (Figure $6)$.

Toll-like receptors (TLRs) are a group of highly conserved molecules that play a vital role in the recognition of pathogen-associated molecular patterns (PAMPs) and in the activation of innate immune responses to infectious agents (Zhang and Lu, 2015). Many studies have implied the TLRs signaling pathway in both antibacterial and anti- 


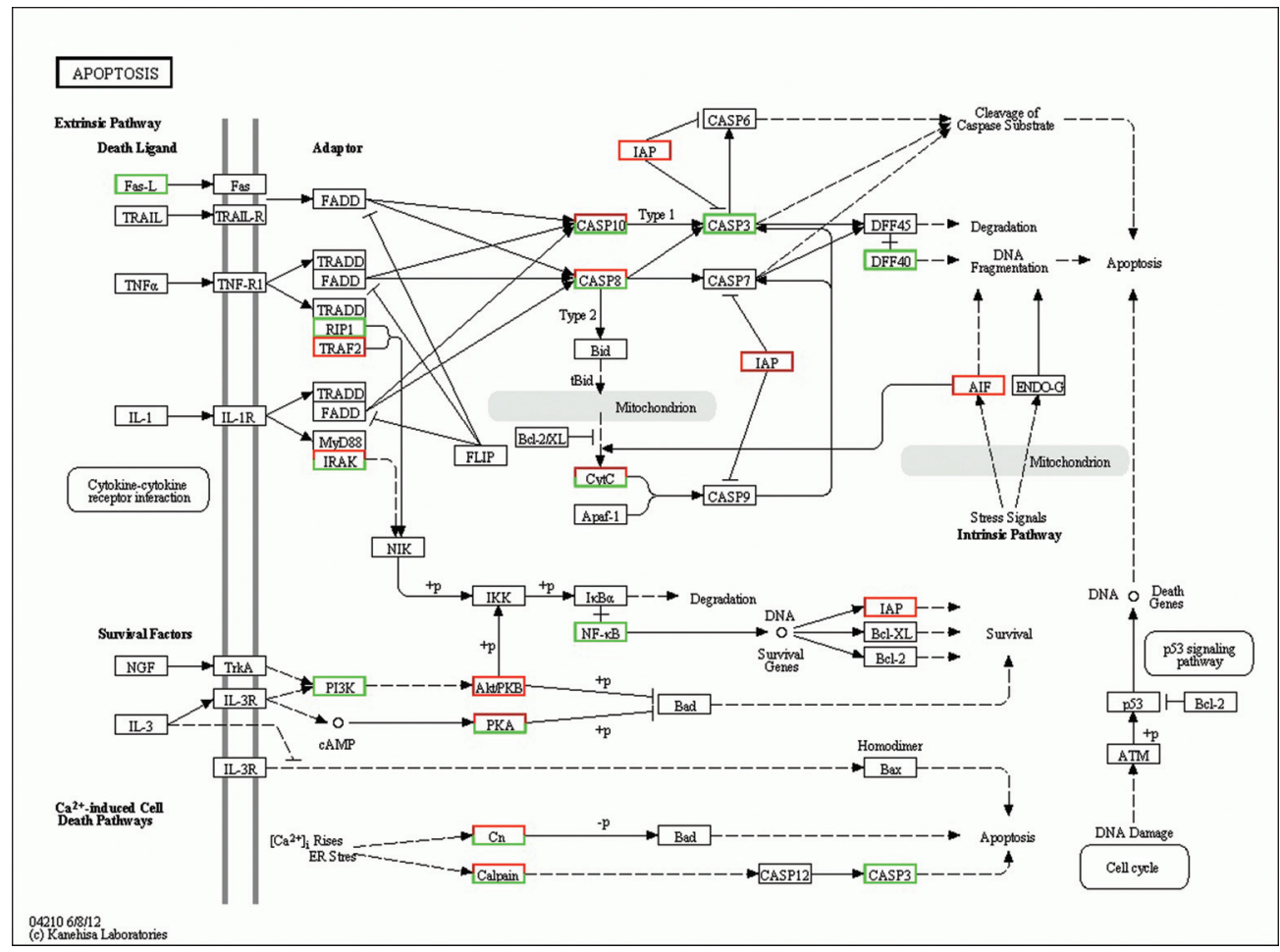

Figure 5 - Significant differentially expressed genes (DEGs) identified by KEGG as involved in the apoptosis signaling pathway. Red boxes indicate significantly increased expression, green boxes indicate significantly decreased expression and blue boxes indicate unchanged expression.

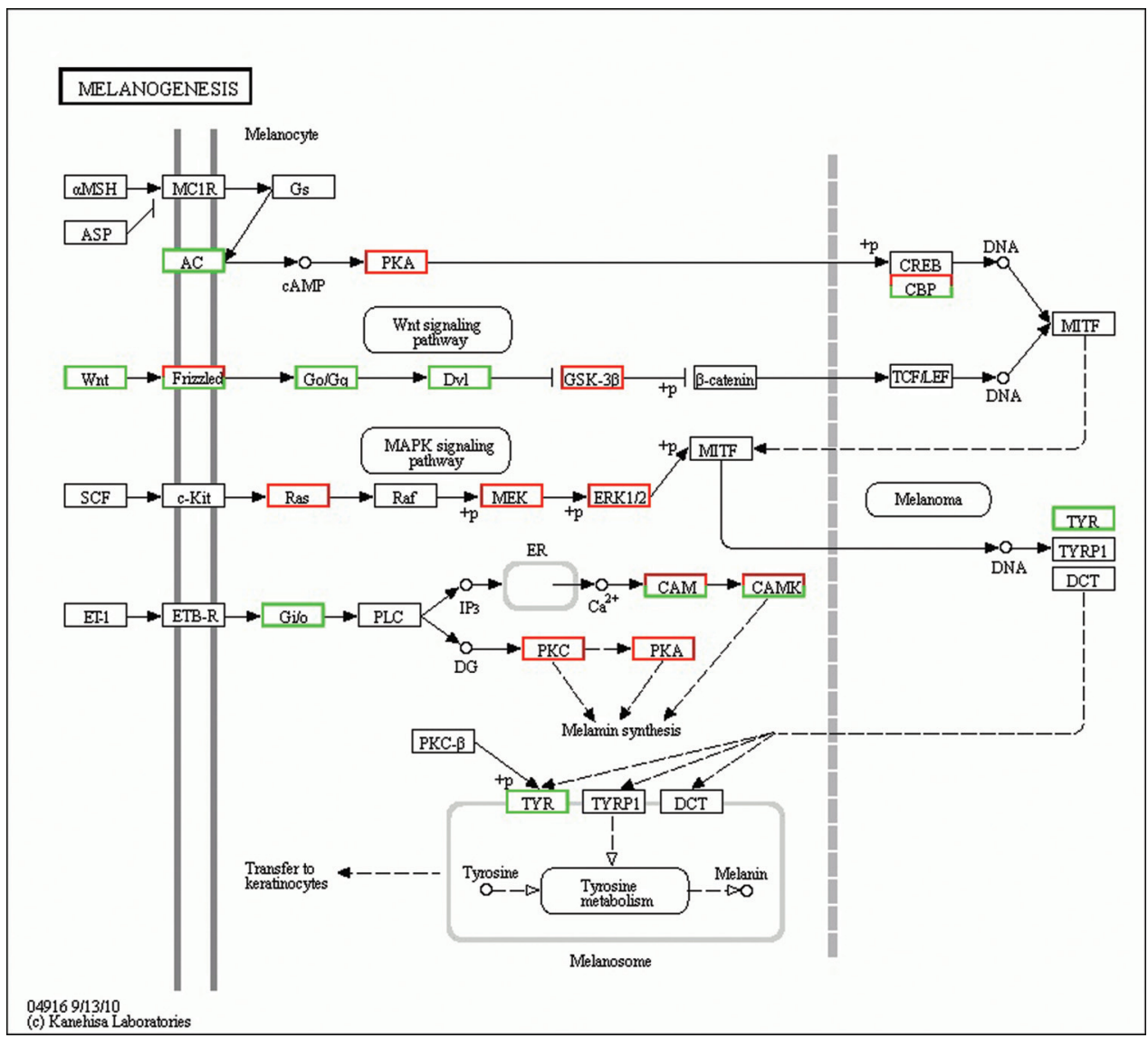

Figure 6 - Significant differentially expressed genes (DEGs) identified by KEGG involved in the melanogenesis signaling pathway. Red boxes indicate significantly increased expression, green boxes indicate significantly decreased expression, and black boxes indicate unchanged expression. 


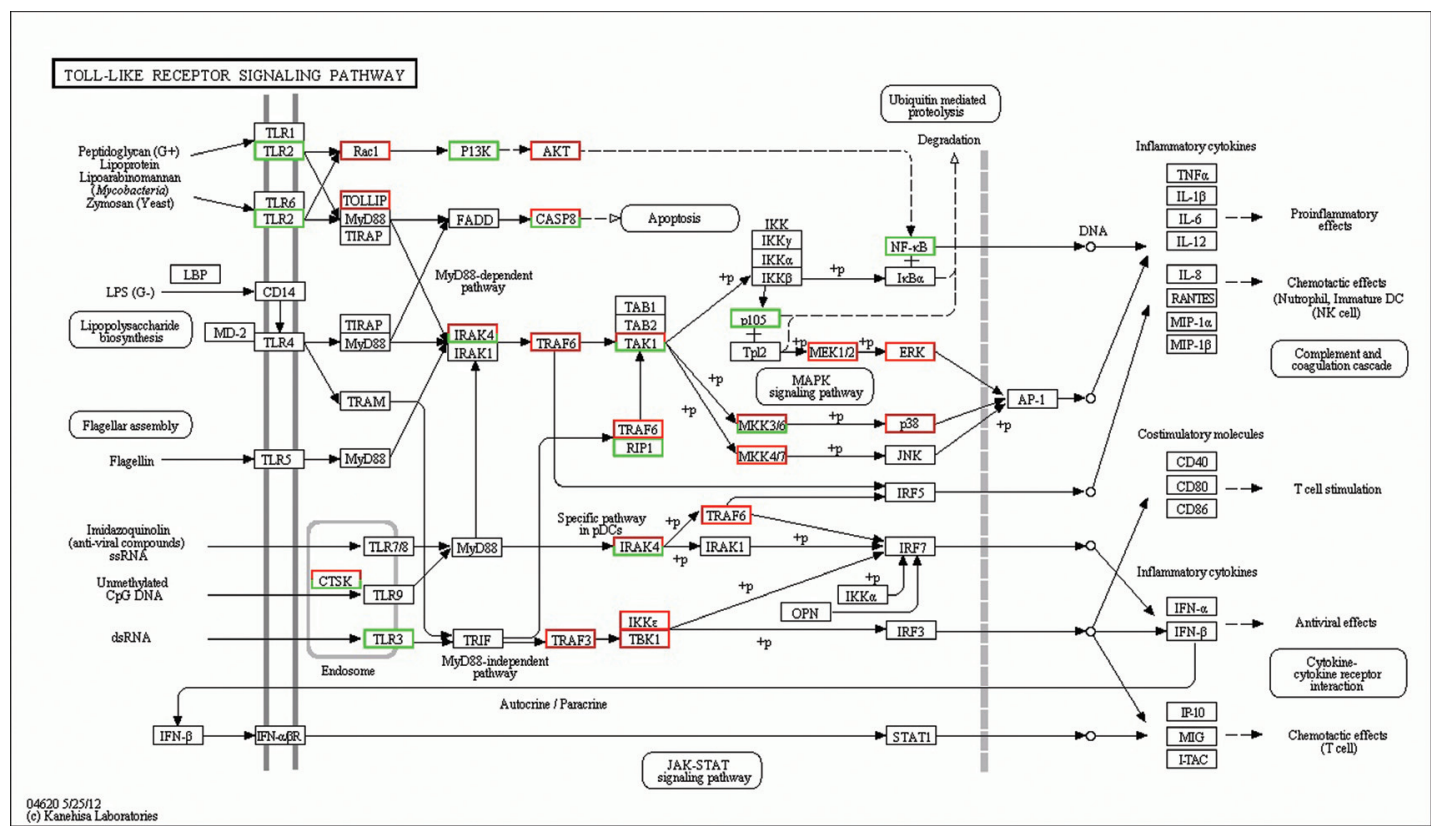

Figure 7 - Significant differentially expressed genes (DEGs) identified by KEGG involved in the Toll-like receptors (TLRs) signaling pathway. Red boxes indicate significantly increased expression, green boxes indicate significantly decreased expression, and black boxes indicate unchanged expression.

fungal defense (De Nardo, 2015). In this study, 66 innate immunity-related genes in the TLRs signaling pathway were significantly differentially expressed, including 49 significantly up-regulated genes and 17 significantly down-regulated genes (Figure 7).

The three abovementioned signaling pathways were significantly changed $(\mathrm{P}<0.01)$ between $\mathrm{GN}$ and $\mathrm{GW}$, which suggests that they may play an important role in crayfish antiviral immunity responses. These results could provide new insights for future research on crayfish antiviral immunity.

In conclusion, many genes and pathways related to innate immunity were modified after WSSV infection of crayfish gills. Leveraging the gene expression changes into a model of altered network functions could provide new insights into the crayfish antiviral immunity mechanism and could also highlight candidate proteins that should be targeted to solve viral disease problems in the crayfish breeding process.

\section{Acknowledgments}

This work was financially supported by the National Natural Science Foundation of China (Grant No. 31460698).

\section{References}

Ali MY, Pavasovic A, Mather PB and Prentis PJ (2015) Transcriptome analysis and characterisation of gill-expressed carbonic anhydrase and other key osmoregulatory genes in freshwater crayfish Cherax quadricarinatus. Data Brief 5:187-193.
Banani H, Marcet-Houben M, Ballester AR, Abbruscato P, González-Candelas L, Gabaldón T and Spadaro D (2016) Genome sequencing and secondary metabolism of the postharvest pathogen Penicillium griseofulvum. BMC Genomics 17:e19.

Chen K, Li E, Li T, Xu C, Wang X, Lin H, Qin JG and Chen L (2015) Transcriptome and molecular pathway analysis of the hepatopancreas in the Pacific White Shrimp Litopenaeus vannamei under chronic low-salinity stress. PLoS One 7:e0131503.

Chen K, Li E, Xu Z, Li T, Xu C, Qin JG and Chen L (2015) Comparative transcriptome analysis in the hepatopancreas tissue of Pacific White Shrimp Litopenaeus vannamei fed different lipid sources at low salinity. PLoS One 12:e0144889.

Christie AE, Chi M, Lameyer TJ, Pascual MG, Shea DN, Stanhope ME, Schulz DJ andDickinson PS (2015) Neuropeptidergic signaling in the American Lobster Homarus americanus: New insights from high-throughput nucleotide sequencing. PLoS One 12:e0145964.

Clavero-Salas A, Sotelo-Mundo RR, Gollas-Galván T, Hernández-López J, Peregrino-Uriarte AB, Muhlia-Almazán A and Yepiz-Plascencia G (2007) Transcriptome analysis of gills from the white shrimp Litopenaeus vannamei infected with White Spot Syndrome Virus. Fish Shellfish Immunol 2:459-472.

Conesa A, Götz S, García-Gómez JM, Terol J, Talón M and Robles M (2005) Blast2GO: A universal tool for annotation, visualization and analysis in functional genomics research. Bioinformatics 18:3674-3676.

De Nardo D (2015) Toll-like receptors: Activation, signalling and transcriptional modulation. Cytokine 2:181-189.

Dedeine F, Weinert LA, Bigot D, Josse T, Ballenghien M, Cahais V, Galtier N and Gayral P (2015) Comparative analysis of transcriptomes from secondary reproductives of three Reticulitermes termitespecies. PLoS One 12:e145596. 
Di Lena P, Domeniconi G, Margara L and Moro G (2015) GOTA: GO term annotation of biomedical literature. BMC Bioinformatics 16:e346.

Du ZQ and Jin YH (2015) Molecular characterization and antibacterial activity analysis of two novel penaeidin isoforms from Pacific White Shrimp, Litopenaeus vannamei. Appl Biochem Biotechnol 8:1607-1620.

Du ZQ, Ren Q, Zhao XF and Wang JX (2009) A double WAP domain (DWD)-containing protein with proteinase inhibitory activity in Chinese white shrimp, Fenneropenaeus chinensis. Comp Biochem Physiol B Biochem Mol Biol 2:203-210.

Du ZQ, Li XC, Wang ZH, Zhao XF and Wang JX (2010) A single WAP domain (SWD)-containing protein with antipathogenic relevance in red swamp crayfish, Procambarus clarkii. Fish Shellfish Immunol 1:134-142.

Du ZQ, Lan JF, Weng YD, Zhao XF and Wang JX (2013) BAX inhibitor-1 silencing suppresses white spot syndrome virus replication in red swamp crayfish, Procambarus clarkii. Fish Shellfish Immunol 1:46-53.

Du ZQ, Yuan JJ and Ren DM (2015) A novel single WAP domain-containing protein isoform with antibacterial relevance in Litopenaeus vannamei. Fish Shellfish Immunol 2:478-484.

Egas C, Pinheiro M, Gomes P, Barroso C and Bettencourt R (2012) The transcriptome of Bathymodiolus azoricus gill reveals expression of genes from endosymbionts and freeliving deep-sea bacteria. Mar Drugs 8:1765-1783.

Elmore S (2007) Apoptosis: A review of programmed cell death. Toxicol Pathol 4:495-516.

Ermolaeva MA and Schumacher B (2014) Insights from the worm: The $C$ elegans model for innate immunity. Semin Immunol 4:303-309.

Feng D, Li Q, Yu H, Zhao X and Kong L (2015) Comparative transcriptome analysis of the Pacific Oyster Crassostrea gigas characterized by shell colors: Identification of genetic bases potentially involved in pigmentation. PLoS One 12:e0145257.

Gao Y, Zhang X, Wei J, Sun X and Yuan J (2015) Whole transcriptome analysis provides insights into molecular mechanisms for molting in Litopenaeus vannamei. PLoS One 12:e0144350.

Garcia-Seco D, Zhang Y, Gutierrez-Mañero FJ, Martin C and Ramos-Solano B (2015) RNA-Seq analysis and transcriptome assembly for blackberry (Rubus sp Var Lochness) fruit. BMC Genomics 16:e5.

Gupta P, Goel R, Agarwal AV, Asif MH, Sangwan NS, Sangwan RS and Trivedi PK (2015) Comparative transcriptome analysis of different chemotypes elucidates withanolide biosynthesis pathway from medicinal plant Withania somnifera. Sci Rep 5:e18611.

He W, Zhuang H, Fu Y, Guo L, Guo B, Guo L, Zhang X and Wei Y (2015) De novo transcriptome assembly of a Chinese Locoweed (Oxytropis ochrocephala) species provides insights into genes associated with drought, salinity, and cold tolerance. Front Plant Sci 6:e1086.

Igney FH and Krammer PH (2002) Death and anti-death: Tumour resistance to apoptosis. Nat Rev Cancer 4:277-288.

Jiang H, Xing Z, Lu W, Qian Z, Yu H and Li J (2014) Transcriptome analysis of red swamp crawfish Procambarus clarkii re- veals genes involved in gonadal development. PLoS One 8:e105122.

Kim K (2015) Effect of ginseng and ginsenosides on melanogenesis and their mechanism of action. J Ginseng Res 1:1-6.

Lai ZX and Lin YL (2013) Analysis of the global transcriptome of longan (Dimocarpus longan Lour) embryogenic callus using Illumina paired-end sequencing. BMC Genomics 14:e561.

Langmead B and Salzberg SL (2012) Fast gapped-read alignment with Bowtie 2. Nat Methods 4:357-359.

Leng X, Jia H, Sun X, Shangguan L, Mu Q, Wang B and Fang J (2015) Comparative transcriptome analysis of grapevine in response to copper stress. Sci Rep 5:e17749.

Li D, Liang Y, Wang X, Wang L, Qi M, Yu Y and Luan Y (2015) Transcriptomic analysis of Musca domestica to reveal key genes of the prophenoloxidase-activating system. G3 (Bethesda) 9:1827-1841.

Li S, Zhang X, Sun Z, Li F and Xiang J (2013) Transcriptome analysis on Chinese shrimp Fenneropenaeus chinensis during WSSV acute infection. PLoS One 3:e58627.

Li ST, Zhang P, Zhang M, Fu CH, Zhao CF, Dong YS, Guo AY and $\mathrm{Yu} \mathrm{LJ} \mathrm{(2012a)} \mathrm{Transcriptional} \mathrm{profile} \mathrm{of} \mathrm{Taxus}$ chinensis cells in response to methyl jasmonate. BMC Genomics 13:295.

Li Y, Deng W, Yang K and Wang W (2012b) The expression of prophenoloxidase mRNA in red swamp crayfish, Procambarus clarkii, when it was challenged. Genomics 6:355-360.

Livak KJ and Schmittgen TD (2001) Analysis of relative gene expression data using real-time quantitative PCR and the 2(-Delta Delta C(T)). Methods 4:402-408.

Lu X, Kim H, Zhong S, Chen H, Hu Z and Zhou B (2014) De novo transcriptome assembly for rudimentary leaves in Litchi chinesis Sonn and identification of differentially expressed genes in response to reactive oxygen species. BMC Genomics 15:e805.

Manfrin C, Tom M, De Moro G, Gerdol M, Giulianini PG and Pallavicini A (2015) The eyestalk transcriptome of red swamp crayfish Procambarus clarkia. Gene 1:28-34.

Mao XZ, Cai T, Olyarchuk JG and Wei LP (2005) Automated genome annotation and pathway identification using the KEGG Orthology $(\mathrm{KO})$ as a controlled vocabulary. Bioinformatics 19:3787-3793.

Martin JA and Wang Z (2011) Next-generation transcriptome assembly. Nat Rev Genet 10:671-682.

Mortazavi A, Williams BA, McCue K, Schaeffer L and Wold B (2008) Mapping and quantifying mammalian transcriptomes by RNA-Seq. Nat Methods 7:621-628.

Mousavi S, Alisoltani A, Shiran B, Fallahi H, Ebrahimie E, Imani A and Houshmand S (2014) De novo transcriptome assembly and comparative analysis of differentially expressed genes in Prunus dulcis Mill in response to freezing stress. PLoS One 8:e104541.

Ramos I and Fernandez-Sesma A (2015) Modulating the innate immune response to influenza A virus: Potential therapeutic use of anti-inflammatory drugs. Front Immunol 6:e361.

Robinson MD, McCarthy DJ and Smyth GK (2010) EdgeR: A Bioconductor package for differential expression analysis of digital gene expression data. Bioinformatics 1:139-140. 
Shen H, Hu Y, Ma Y, Zhou X, Xu Z, Shui Y, Li C, Xu P and Sun X (2014) In-depth transcriptome analysis of the red swamp crayfish Procambarus clarkii. PLoS One 10:e110548.

Taffoni C and Pujol N (2015) Mechanisms of innate immunity in C elegans epidermis. Tissue Barriers 4:e1078432.

Tatusov RL, Fedorova ND, Jackson JD, Jacobs AR, Kiryutin B, Koonin EV, Krylov DM, Mazumder R, Mekhedov SL, Nikolskaya AN, et al. (2003) The COG database: An updated version includes eukaryotes. BMC Bioinformatics $1: e 41$.

Wang P, Wang J, Su YQ, Mao Y, Zhang JS, Wu CW, Ke QZ, Han KH, Zheng WQ and Xu ND (2015) Transcriptome analysis of the Larimichthys crocea liver in response to Cryptocaryon irritans. Fish Shellfish Immunol 48:1-11.

Young MD, Wakefield MJ, Smyth GK and Oshlack A (2010) Gene ontology analysis for RNA-seq: Accounting for selection bias. Genome Biol 2:R14.

Zhang E and Lu M (2015) Toll-like receptor (TLR)-mediated innate immune responses in the control of hepatitis $\mathrm{B}$ virus (HBV) infection. Med Microbiol Immunol 1:11-20.

Associate Editor: Houtan Noushmehr

License information: This is an open-access article distributed under the terms of the Creative Commons Attribution License (type CC-BY), which permits unrestricted use, distribution and reproduction in any medium, provided the original article is properly cited. 